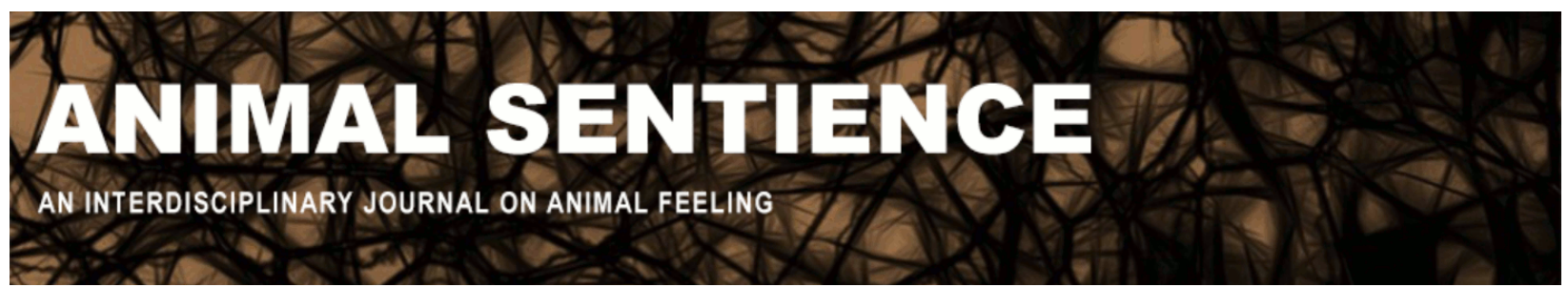

Irvine, Leslie (2017) Animal pain and the social role of science. Animal Sentience 16(18)

DOI: $10.51291 / 2377-7478.1268$

Date of submission: 2017-11-27

Date of acceptance: 2017-11-29

(c)

This article has appeared in the journal Animal

Sentience, a peer-reviewed journal on animal

cognition and feeling. It has been made open access,

free for all, by WellBeing International and deposited

in the WBI Studies Repository. For more information,

please contact

wbisr-info@wellbeingintl.org.

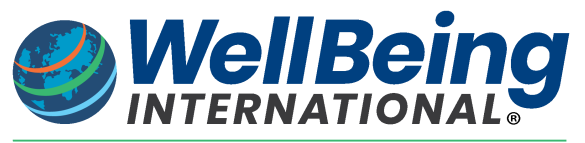

SOLUTIONS FOR PEOPLE, ANIMALS AND ENVIRONMENT 


\title{
Animal pain and the social role of science
}

Commentary on Birch on Precautionary Principle

\author{
Leslie Irvine \\ Department of Sociology \\ University of Colorado at Boulder
}

\begin{abstract}
Assuming that all animals are sentient would mean ending their use in most scientific research. This does not necessarily imply an unscientific or anti-scientific stance. Examining the social role of science reveals its considerable investment in preserving the status quo, including the continued use of animal subjects. From this perspective, the use of animal subjects is a custom that science could move beyond, rather than a methodological requirement that it must defend.
\end{abstract}

Leslie Irvine is Professor of Sociology at the University of Colorado at Boulder. Her research focuses on the roles of animals in society. She has studied animal sheltering, gender in veterinary medicine, images of animals in popular culture, animal abuse, and animal welfare in disasters. Her most recent book, My Dog Always Eats First, examines homeless people's relationships with their pets. Her previous books include If You Tame Me: Understanding our Connection with Animals and Filling the Ark: Animal Welfare in Disasters. www.colorado.edu/sociology/leslie-irvine

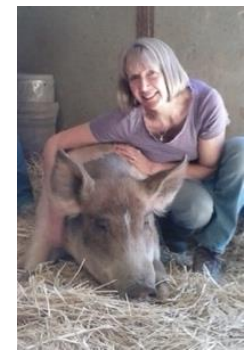

Jonathan Birch (2017) has taken up the task of clarifying the evidence of sentience required to provide an animal basic protection from harm. This is a valuable task. I found his paper carefully reasoned and thought-provoking. I am honored to join the list of scholars in conversation about his work.

One way around the need to set an evidential bar would be to assume that all animals are sentient, unless proven otherwise. Birch presents this option in section 2 of his target article. Arthur Reber (2016) has already supported this in his commentary, using his Cellular Basis of Consciousness model (2016). Birch deems this option "extreme" because "it would invite the charge of being unscientific or anti-scientific." It would make research on animal sentience unnecessary and irrelevant. Moreover, because it would rule out the use of even fruit flies and nematodes, common models in bioscience, it would create "significant practical obstacles to biomedical research." I'm reminded of the scene in the original "Ghostbusters," where Bill Murray famously said, "Back off, man. I'm a scientist."

From this, I conclude that the freedom to harm animals must be preserved so that scientists can find out how much harm animals can take. Moreover, we need to continue harming even the smallest of animals in the interest of "science."

I am neither a biologist nor a philosopher. Rather, I am a sociologist, trained to question the social role of science, the nature of expertise, and the conditions under which knowledge is produced. Science's main interest is self-preservation and protecting itself against threats to authority. Concerns about being "anti-scientific" make sense only in contrast to a view of science 
as objective and rational, and of scientists as neutral and autonomous. In light of the vast science studies literature, I very much doubt that Birch believes this propaganda, but his model depends on an acceptance of Kuhnian "normal scientific standards."

Against the view of objectivity and neutrality, science's ties to commercial interests have made truly independent research very nearly impossible. In academia and government, the autonomy scientists traditionally enjoyed "has been steadily eroded by the short-term, profitdriven interests of corporations" (Marshall \& Picou 2008, p. 244). Because profits require an unending stream of "needs," any objections to the use of animals must compete with tales of human suffering, for which more research - on animals - is necessary. In the service of corporate imperatives, anything that can be done to animals will be done to them.

Research indicates that animal researchers seek to preserve the ability to conduct research on animals. For example, a 2012 analysis of animal research ethics committees (IACUCs) at the 25 top American institutions receiving funding from the National Institutes of Health found the committees populated mostly by animal researchers, laboratory veterinarians, and others with a vested interest in continuing animal experiments (Hansen, Goodman, \& Chandna 2012). The imbalance both contributes to "previously-documented committee biases in favor of approving animal experiments" and weakens "input from the few members representing animal welfare and the interests of the general public." Science protects its own.

The "normal scientific standards" and statistical significance that Birch recommends did not reassure me at all. Phrenology, bloodletting, mercury therapy: the list of harmful claims and grotesque procedures that once met "normal scientific standards" knows no end. Where pain is concerned, these standards justified performing open-heart surgery on newborn human infants without anesthesia until the 1980s (Segner 2016). After all, there was no reliable evidence that babies could feel pain, and even if they did, they would not remember it. Moreover, while statistically significant evidence of the presence of an indicator of sentience sounds like an acceptable standard, the academic and popular literatures have documented the pitfalls of significance testing. The common practice known as p-hacking, where a researcher obtains significance by omitting data or running endless tests, has created what some call a crisis of reproducibility, that bedrock of scientific method (Head et al. 2015).

I support the spirit of Birch's approach, but I want to think beyond what science "needs." Rather, I want science to think beyond what it customarily needs, which is an endless supply of other animals. Let's make the third of the 3Rs mean replace animals, not just replace them with "lower" animals. If this comes across as anti-science, I'll clarify that there is a difference between hostility to science and questioning science's social role. It is possible to appreciate the value of science while keeping a critical eye on its conduct and values. 


\section{References}

Birch, J. (2017). Animal sentience and the precautionary principle. Animal Sentience 16(1). Hansen, L.A., Goodman, J.R., \& Chandna, A. (2012). Analysis of animal research ethics committee membership at American institutions. Animals 2(1), 68-75. doi:10.3390/ani2010068

Head, M.L., Holman, L., Lanfear, R., Kahn, A. T., \& Jennions, M.D. (2015). The extent and consequences of p-hacking in science. PLoS Biology 13(3), e1002106.

Marshall, B.K., \& Picou, J.S. (2008). Postnormal science, precautionary principle, and worst cases: The challenge of twenty-first century catastrophes. Sociological Inquiry 78(2), 230247.

Reber, A.S. (2016). Caterpillars, consciousness and the origins of mind. Animal Sentience 11(1). Segner, H. (2016). Why babies do not feel pain, or: How structure-derived functional interpretations can go wrong. Animal Sentience 3(26). 